\title{
Nursing Home Residents' Level of Knowledge About Urinary Incontinence
}

\author{
Illkim Çıtak Karakaya, Semiha Yenişehir, Mehmet Gürhan Karakaya \\ Department of Physiotherapy and Rehabilitation, Faculty of Health Sciences, Muğla Sıtkı Koçman University, Muğla, Turkey
}

Corresponding Author:

Semiha Yenişehir, PT, MSc

https://orcid.org/0000-0002-3928-2207

Department of Physiotherapy and

Rehabilitation, Faculty of Health

Sciences, Muğla Sıtkı Koçman

University, Kötekli, Muğla 48000,

Turkey

E-mail: ysehir.semiha8@gmail.com

Received: January 10, 2019

Revised: February 1, 2019

Accepted: February 2, 2019

\begin{abstract}
Background: A common problem in nursing home residents, urinary incontinence (UI) can lead to hygiene and skin problems, sleep disturbance, and decreased quality of life. This study evaluated the level of knowledge regarding $\mathrm{UI}$ among nursing home residents in Muğla, Turkey. Methods: This study included 64 (19 females, 45 males) nursing home resident volunteers. Their physical and sociodemographic characteristics; daily living activities (Barthel Index); and the presence, frequency, severity, and type of $\mathrm{UI}$ as well as its impact on daily living were evaluated (International Consultation on Incontinence QuestionnaireShort Form) and history of treatment was queried. An Incontinence Quiz was used to assess the residents' knowledge of incontinence. Results: The participants were living in nursing homes for $34.48 \pm 33.16$ months. Their educational level was low and most were single. The mean Barthel Index score was $89.75 \pm 13.00$. Twenty-five participants had UI (18.8\% urge, $4.7 \%$ stress, $15.6 \%$ mixed/other type), and the mean International Consultation on Incontinence Questionnaire-Short Form score was $8.08 \pm 4.24$. Forty-four percent of the participants had no treatment and none had physiotherapy for incontinence. The mean Incontinence Quiz score was $4.88 \pm 1.96$, indicating a low level of knowledge. The items with the highest ratio of incorrect responses (second and 14th) were related to the causes of incontinence and care seeking. Conclusion: These findings underscore the necessity of increasing knowledge among nursing home residents about the reasons and health care options for UI. Further studies on appropriate strategies to improve UI knowledge in this population will be of great value. (Ann Geriatr Med Res 2019;23:20-26)
\end{abstract}

Key Words: Aged, Geriatric assessment, Incontinence Quiz, Knowledge, Urinary incontinence

\section{INTRODUCTION}

Urinary incontinence (UI), defined as the complaint of any involuntary loss of urine, is a major problem for adults, especially for older women. ${ }^{1-3)}$ More than half of nursing home residents are incontinent ${ }^{2-5)}$ and the prevalence of UI in residents of Turkish nursing homes is $30.0 \%-47.6 \% 0^{6-8)}$

UI may occur in nursing home residents due to neurological diseases, urological and gynecological problems, psychological reasons, and functional impairments. These conditions may affect bladder control and voiding frequency. ${ }^{2)} \mathrm{UI}$ leads to hygiene and skin problems, sleep disturbances, and sexual activity disorders and impairs quality of life by causing negative psychological and social effects such as lack of self-esteem, shame, anxiety, depression, and social isolation. ${ }^{9,10)}$ In addition, UI increases the workload of caregivers and health care costs in nursing homes. ${ }^{10)}$

Although UI is a problem with multifactorial etiology, it can be cured or ameliorated at a large scale with the implementation of appropriate methods, such as lifestyle regulation and behavioral therapy. ${ }^{2)}$ However, many pa- tients feel ashamed and embarrassed by their incontinence and consider UI a taboo subject. In addition, lack of knowledge about UI and a belief that it is a natural result of aging prevent older people, as well as their families and caregivers, from seeking medical help. ${ }^{9-13)}$

Kubik et al. ${ }^{11)}$ suggested that improving knowledge about UI and treatment options would likely lead to increased care seeking. Therefore, a number of studies have investigated the level of knowledge regarding UI in different populations. ${ }^{1,12-23)}$ Most of these studies were conducted on community-dwelling people of different age, sex, and race groups ${ }^{1,12,13,15-23)}$ and few investigated the level of knowledge and practices about UI among nursing home staff. ${ }^{14)}$ Despite being a very important and common problem, research on UI in nursing home residents, especially in Turkey, has mainly focused on its prevalence, correlations with mobility, and impact on quality of life..$^{6-8,24-26)}$ To our knowledge, no study has investigated UI knowledge among nursing home residents. Therefore, this study assessed the level of knowledge regarding UI among nursing home residents. 


\section{MATERIALS AND METHODS}

This questionnaire-based cross-sectional study was conducted on the residents of three nursing homes in Muğla, Turkey, between November 2016 and February 2017. The study included volunteer participants and was performed in accordance with the principles of the Declaration of Helsinki. Administrative and ethical approvals for the study were obtained from the Muğla Family and Social Policies Provincial Directorate and the Scientific Research Ethical Board of Muğla Sıtkı Koçman University (Protocol number: 121), respectively.

Based on their formal registrations, there were a total of 208 residents in participating nursing homes. Some of these residents required specialized care, support, protection, and rehabilitation due to severe physical or mental deterioration and, thus, were being attended at the rehabilitation centers of these nursing homes. Therefore, the eligibility of the remaining 115 nursing home residents was assessed. Among them, 23 participants had visual/hearing problems at a level that prevented their participation in the study, 19 had scores $\leq 24$ points on the Mini-Mental Test, ${ }^{27)}$ and nine declined to participate in the study. As a result, 64 subjects fulfilled the inclusion criteria, signed the informed consent form, and were included in the study. The following information was recorded for these eligible individuals:

- Physical characteristics (age, gender, body weight, height, and body mass index)

- Level of education (literate/primary/secondary/high school/university)

- Marital status (married/single/widowed/divorced)

- Length of stay in the nursing home (months)

- Mobility status (bedridden/independent with assistive equipment [cane/crutches/wheelchair]/completely independent)

- Level of independence in activities of daily living (Turkish version of the Barthel Index) ${ }^{28)}$

- Complaint of UI (yes/no)

- History of treatment for UI (medical/surgical/physiotherapy/none)

- Comorbid illnesses associated with UI (chronic obstructive pulmonary disease, asthma, diabetes, obesity, etc.) (yes/no)

- Use of medication that may contribute to UI (antihypertensive, diuretic, antidepressant, etc.) (yes/no)

- Coping methods for UI (diaper/pad/catheter/penis clamp/none)

- In addition, male participants were questioned regarding their history of prostate problem/surgery (yes/no), while female residents were questioned regarding the:

- Number of pregnancies

- Number of vaginal deliveries

- Number of Cesarean sections

- Type of menopause (natural/surgical-induced)

- History of gynecological surgery (yes/no)
The severity, frequency, and type of UI were assessed using the Turkish version of International Consultation on Incontinence Questionnaire-Short Form (ICIQ-SF). ${ }^{29)}$ The score range of this measure is $0-21$ points, where higher scores indicate greater severity.

The nursing home residents' level of knowledge about UI was assessed using the 14-item Incontinence Quiz (IQ) developed by Branch et al. ${ }^{16)}$. The measure was translated into Turkish by Kara et al. ${ }^{15)}$ and the Turkish version has been shown to be reliable and valid. The participants' responses to each item on the IQ included "agree/disagree/ don't know." The correct answers were "agree" for the first, fourth, sixth, eighth, 10th, and 11th items and "disagree" for the second, third, fifth, seventh, ninth, 12th, 13th, and 14th items. Items marked as "don't know" were scored as incorrect. Each correct answer was assigned 1 point and the total score ranged between 0 and 14 points, where higher scores indicate a higher level of knowledge about UI. ${ }^{15,16)}$

For statistical analysis, IBM SPSS Statistics for MacOSX, version 22.0 (IBM, Armonk, NY, USA) was used. Quantitative variables were described as means \pm standard deviation and qualitative variables as numbers and percentage. The Barthel Index and IQ scores of the continent and incontinent groups were compared by using Mann-Whitney Utests. Statistical significance was set at an alpha level of 0.05 .

\section{RESULTS}

The physical characteristics of the 19 female and 45 male nursing home residents are presented in Table 1 . Their mean length of stay in the nursing home was $34.48 \pm 33.16$ months ( 20 months for women and 40 months for men). Only $31.3 \%$ of the participants had a high school or university degree; the majority (68.7\%) had primary education at most. The percentage of married participants was low and most participants were single (Table 1).

Only one of the participants $(1.6 \%)$ was bedridden, 16 (25.0\%) were independent with assistive equipment, and $47(73.4 \%)$ were independent. None of the participants reported using a wheelchair, one used crutches (1.6\%), and 15 (23.4\%) used canes (Table 2). The mean Barthel Index score of the participants was $89.75 \pm 13.00$ (minimum $=50$, maximum $=100$ ), indicating a moderate dependence in activities of daily living. ${ }^{28)}$ The Barthel Index scores of participants with $(88.48 \pm 13.69$ points) and without $(90.54 \pm 12.68$ points) UI complaint were similar $(\mathrm{p}=0.440)$ (Table 2). According to obstetrical and gynecological history assessment of the female residents, the number of pregnancies and deliveries ranged from 0-8, none had delivered by Cesarean section, all had experienced natural menopause, and 31.6\% had undergone gynecological surgery. In addition, one-third of the male residents (33.3\%) reported having had prostate problem/surgery.

Among all participants, 12 women and 13 men (39.1\%) 
Table 1. Physical and sociodemographic characteristics of the participants

\begin{tabular}{|lccc|}
\hline & Female $(\mathrm{n}=19)$ & Male $(\mathrm{n}=45)$ & Total $(\mathrm{n}=64)$ \\
\hline Age $(\mathrm{y})$ & $78.21 \pm 10.03$ & $71.29 \pm 7.21$ & $73.34 \pm 8.67$ \\
\hline Height $(\mathrm{cm})$ & $159.41 \pm 6.82$ & $166.69 \pm 26.85$ & $164.62 \pm 23.17$ \\
\hline Weight $(\mathrm{kg})$ & $66.82 \pm 13.34$ & $74.76 \pm 15.85$ & $72.51 \pm 15.50$ \\
\hline Body mass index $\left(\mathrm{kg} / \mathrm{m}^{2}\right)$ & $26.31 \pm 6.09$ & $25.38 \pm 5.07$ & $25.64 \pm 5.34$ \\
\hline Length of stay at the nursing home $(\mathrm{mo})$ & $20.21 \pm 15.62$ & $40.51 \pm 36.73$ & $34.48 \pm 33.16$ \\
\hline Level of education & & & \\
\hline Literate & $10(52.6)$ & $22(48.8)$ & $32(50.0)$ \\
\hline Primary school & $2(10.5)$ & $10(22.2)$ & $12(18.8)$ \\
\hline Secondary school & $0(0)$ & $0(0)$ & $0(0)$ \\
\hline High school & $4(21.1)$ & $6(13.3)$ & $10(15.6)$ \\
\hline University & $3(15.8)$ & $7(15.6)$ & $10(15.6)$ \\
\hline Marital status & & $8(17.8)$ & $11(17.2)$ \\
\hline Married & $3(15.8)$ & $11(24.4)$ & $17(26.6)$ \\
\hline Divorced & $6(31.6)$ & $18(40.0)$ & $28(43.8)$ \\
\hline Widowed & $10(52.6)$ & $8(17.8)$ & $8(12.5)$ \\
\hline Single & $0(0)$ & \\
\hline
\end{tabular}

Values are presented as mean \pm standard deviation or number (\%).

Table 2. Functional status of the participants

\begin{tabular}{|lccc|}
\hline & Female $(\mathrm{n}=19)$ & Male $(\mathrm{n}=45)$ & Total $(\mathrm{n}=64)$ \\
\hline Bedridden & $1(5.3)$ & $0(0)$ & $1(1.6)$ \\
\hline Independent & $9(47.4)$ & $78(84.4)$ & $47(73.4)$ \\
\hline Independent with assistive equipment & $9(47.4)$ & $0(15.6)$ & $16(25.0)$ \\
\hline Wheelchair & $0(0)$ & $0(0)$ & $0(0)$ \\
\hline Crutches & $1(5.3)$ & $7(15.6)$ & $1(1.6)$ \\
\hline Canes & $8(42.1)$ & & $15(23.4)$ \\
\hline Barthel Index Score & & $93.41 \pm 8.25$ & $89.75 \pm 13.00$ \\
\hline All participants & $81.84 \pm 17.50$ & $93.64 \pm 7.78$ & $88.48 \pm 13.69$ \\
\hline Participants with UI complaint & $83.75 \pm 16.40$ & $93.33 \pm 8.54$ & $90.54 \pm 12.68$ \\
\hline Participants without UI complaint & $78.57 \pm 20.15$ & & \\
\hline
\end{tabular}

Values are presented as number (\%) or mean \pm standard deviation.

UI, urinary incontinence.

complained of UI. When incontinent participants were questioned regarding their treatment history for UI, 56.0\% reported medical treatment, 40.0\% had no treatment, and none had received physiotherapy (Table 3). Comorbid illnesses associated with UI and use of medication that may contribute to UI were reported by $48.7 \%$ of all participants and $56.0 \%$ of incontinent participants. Table 3 presents the comorbid illnesses associated with UI in incontinent women and men. Four incontinent residents had more than one comorbid illness associated with UI. Twentyeight percent of incontinent participants reported that they were using diapers as a coping method with UI, while 72\% reported no coping method. According to ICIQ-SF data of all nursing home residents, $18.8 \%$ had urge, $4.7 \%$ had stress, 7.8\% had mixed, and 7.8\% had other types of UI. Among incontinent participants, the most common type of UI was also urge incontinence (48.0\%) (Table 3).

The mean ICIQ-SF score, which reflects the total score of the amount and frequency of UI and its impact on quality of life, was $8.08 \pm 4.24$ points overall over 21 points among incontinent participants. The cut-off score for the Turkish ICIQ-SF is eight. ${ }^{29)}$ Therefore, in this study, 50.0\% of incontinent women and $15.4 \%$ of incontinent men had ICIQ-SF scores $\geq 8$ points and were considered to have bothersome UI. Among incontinent men, 61.5\% leaked urine approximately once a week or less, while $33.3 \%$ each of incontinent women leaked twice or three times a week and approximately once a day, respectively, according to the ICIQ-SF (Table 4).

None of the nursing home residents correctly answered all of the IQ questions. Their mean IQ score was $4.88 \pm 1.96$ (minimum=1, maximum=9), indicating a low level of UI knowledge. Continent and incontinent residents had similar IQ scores $(4.97 \pm 2.15$ and $4.72 \pm 1.67$ points, respectively) ( $\mathrm{p}=0.564)$. The second ("involuntary loss of urine, often called leaky bladder or urinary incontinence, is one of the results of normal aging") and 14th ("most people with involuntary urine loss talk to their doctors about it") items on the IQ had the highest rates of incorrect responses (84.4\%). These were followed by the third ("most 
Table 3. Participant complaints, type and treatment history of urinary incontinence, and comorbid illnesses associated with UI according to gender

\begin{tabular}{|c|c|c|c|}
\hline & Female & Male & Total \\
\hline All participants & 19 & 45 & 64 \\
\hline \multicolumn{4}{|l|}{ UI complaint } \\
\hline Yes & $12(63.2)$ & $13(28.8)$ & $25(39.1)$ \\
\hline No & $7(36.8)$ & $32(71.1)$ & $39(60.9)$ \\
\hline Incontinent participants & 12 & 13 & 25 \\
\hline \multicolumn{4}{|l|}{ UI type } \\
\hline Stress & $2(16.7)$ & $1(7.7)$ & $3(12.0)$ \\
\hline Urge & $5(41.7)$ & 7 (53.9) & $12(48.0)$ \\
\hline Mixed & $4(33.3)$ & $1(7.7)$ & $5(20.0)$ \\
\hline Other & $1(8.3)$ & $4(30.8)$ & $5(20.0)$ \\
\hline \multicolumn{4}{|l|}{ UI treatment } \\
\hline Medical & $6(50.0)$ & $8(61.5)$ & $14(56.0)$ \\
\hline Surgery & $0(0)$ & $1(7.7)$ & $1(4.0)$ \\
\hline Physiotherapy & $0(0)$ & $0(0)$ & $0(0)$ \\
\hline No treatment & $6(50.0)$ & $4(30.8)$ & $10(40.0)$ \\
\hline \multicolumn{4}{|c|}{ Comorbid illnesses associated with UI } \\
\hline COPD & $0(0)$ & $2(15.4)$ & $2(8.0)$ \\
\hline Asthma & $2(16.7)$ & $3(23.1)$ & $15(20.0)$ \\
\hline Diabetes & $6(50.0)$ & $2(15.4)$ & $8(32.0)$ \\
\hline Obesity & $1(8.3)$ & $2(15.4)$ & $3(12.0)$ \\
\hline
\end{tabular}

Values are presented as number (\%).

UI, urinary incontinence; COPD, chronic obstructive pulmonary disease.

people will involuntarily or accidentally lose control of their urine on a regular basis by the time they are 85") and 12th ("involuntary urine loss is caused by only one or two conditions") items, with incorrect response rates of $82.8 \%$ (Fig. 1). The items with the highest incorrect answer rates were related to the causes of UI and treatment seeking for the problem. The sixth item ("there are exercises that can help control urine if one leaks when they cough, sneeze, or laugh") had the highest number of "I don't know" responses and was related to knowledge of exercises to help urine control. The IQ items with the highest correct rates were the first ("most people who currently have involuntary urine loss live normal lives") and 10th ("involuntary loss of urine can be caused by several easily treatable medical conditions") items (70.3\% and 60.9\%, respectively) (Fig. 1).

\section{DISCUSSION}

This study, which assessed UI knowledge among nursing home residents in Muğla Province, Turkey, showed that the residents had poor knowledge of UI. Consideration of their sociodemographic characteristics, mobility status, and level of dependence in activities of daily living of the sample indicated that they were similar to related sample characteristics presented in various articles on individuals living in different Turkish nursing homes. Therefore, the sample in the present study reflects the general characteristics of Turkish nursing home residents. ${ }^{8,30,31)}$
Table 4. Frequency and severity of urinary incontinence according to the ICIQ-SF

\begin{tabular}{lllc}
\hline \multicolumn{1}{|c}{ ICIQ-SF items } & $\begin{array}{c}\text { Female } \\
(\mathrm{n}=12)\end{array}$ & $\begin{array}{c}\text { Male } \\
(\mathrm{n}=13)\end{array}$ & $\begin{array}{c}\text { Total } \\
(\mathrm{n}=25)\end{array}$ \\
\hline $\begin{array}{lllc}\text { How often do you leak? } \\
\text { Never }\end{array}$ & $0(0)$ & $0(0)$ & 0 \\
\hline Approximately once a week or less & $2(16.7)$ & $8(61.5)$ & $10(40.0)$ \\
\hline $\begin{array}{l}\text { Two or three times a week } \\
\text { Approximately once a day }\end{array}$ & $4(33.3)$ & $2(15.4)$ & $6(24.0)$ \\
A few times a day & $4(33.3)$ & $1(7.7)$ & $5(20.0)$ \\
\hline Always & $2(16.7)$ & $1(7.7)$ & $3(12.0)$ \\
How much urine leaks? & $0(0)$ & $1(7.7)$ & $1(4.0)$ \\
\hline None & & & \\
A small amount & $0(0)$ & $0(0)$ & $0(0)$ \\
\hline A moderate amount & $6(50.0)$ & $11(84.6)$ & $17(68.0)$ \\
\hline A large amount & $5(41.7)$ & $1(7.7)$ & $6(24.0)$ \\
\hline
\end{tabular}

Values are presented as number (\%).

ICIQ-SF, International Consultation on Incontinence QuestionnaireShort Form.

The prevalence of UI in this study sample was 39.1\% (63.2\% in female and 28.8\% in male), a slightly higher prevalence than that reported by Cankurtaran et al. ${ }^{8)}$ in Kayseri nursing homes (34.5\%) and slightly lower than that reported by Ergün et al. ${ }^{26)}$ in İstanbul nursing homes (45\%). Subject-related large-scale studies in the United States, ${ }^{32)}$ Sweden, ${ }^{14)}$ and Brazil ${ }^{10)}$ showed prevalence rates of UI in nursing homes of 30\%, 51.5\%, and 58.9\%, respectively. These findings indicate that UI is a common problem among the residents of nursing homes both in Turkey and other countries.

According to ICIQ-SF data, the most common type of UI was urge incontinence $(18.8 \%$ of the whole sample and $48.0 \%$ of incontinent residents). This finding is consistent with those of the studies by $\mathrm{Na}$ et al. ${ }^{33)}$ (44.3\% urge) and Lee et al. ${ }^{34)}$ (47.2\% urge), which reported urge incontinence to be the most common type of UI in the older population. Analysis of the frequency of UI in incontinent residents revealed that $20.0 \%$ of the participants leaked urine approximately once a day, similar to the study sample assessed by Lee et al. ${ }^{34)}$ In both studies, the percentage of participants leaking urine more frequently than once a day was low $(16.0 \%$ in this study and $~ 9 \%$ in the study by Lee et al. ${ }^{34)}$.

Analysis of the treatment approaches for UI indicated that the most common method was medical treatment (56.0\%), 40.0\% of the participants did not receive any treatment, and none received physiotherapy and/or behavioral therapy. However, in a large-scale study by Jumadilova et al. ${ }^{32)}$ conducted at 378 skilled nursing facilities from across the United States, the methods commonly used for UI in the older people living in nursing homes included behavior training methods such as bladder training and timed voiding, while drug treatment was less frequent (8\%) and only applied to individuals with very severe UI.

In this study, participants with UI generally did not use 
14-Most people with involuntary urine loss talk to their doctors about it.

13-Most physicians ask their older patients whether they have bladder control problems.

12-Involuntary urine loss is caused by only one or two conditions.

11-Many over the counter medications can cause involuntary urine loss.

10 -Involuntary loss of urine can be casued by several easily treatable medical conditions.

9-Once people start to lose control of their urine on a regulary basis they usually never regain complete control over it again.

8-Many people with involuntary urine loss can be cured and almost everyone can experience significant improvement.

7-The best treatment for involuntary urine loss is usually surgery.

6 -There are exercises that can help control urine if one leaks when they coughy, sneeze or laughy.

5-Other than pads, diapers, and catheters, little can be done to treat or cure involuntary urine loss.

4-Women are more likely than men to develop urinary incontinence.

3-Most people will involuntarily or accidentally lose control of their urine on a regular basis by the time they are 85 .

2-Involuntary loss of urine, often called leaky bladder or urinary incontinence, is one of the results of normal aging.

1-Most people who currently have involuntary urine loss normal lives.

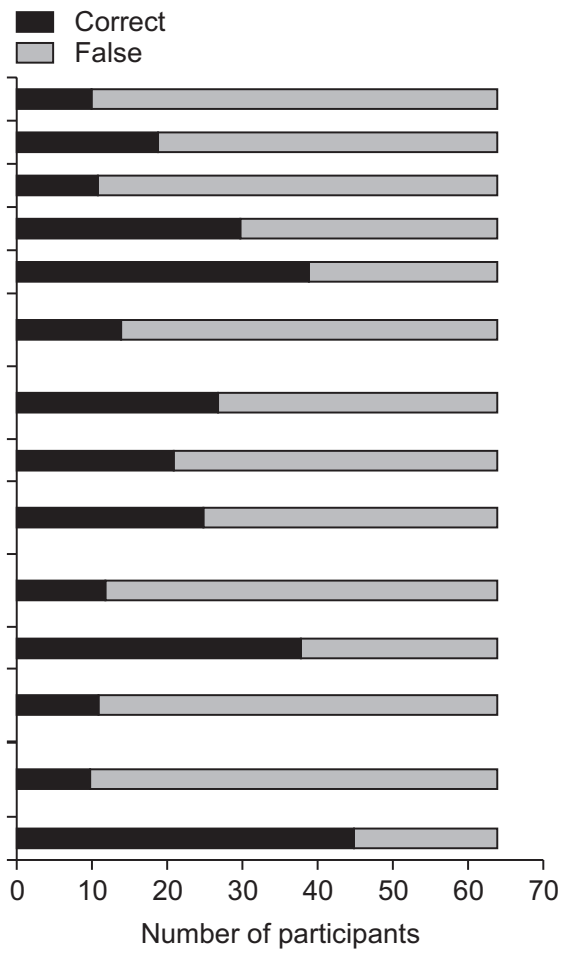

Fig. 1. Number of participants with correct and incorrect responses to Incontinence Quiz items.

a coping method (72\%) and only $28 \%$ were using diapers/ pads. This finding corresponds with those of Jung et al., ${ }^{35)}$ who reported that only 20\% of older Alzheimer's patients used diapers/pads. Göral Türkcü and Kukulu ${ }^{25)}$ and Demirci et al. $^{24)}$ reported significantly higher percentages of participants in nursing homes using diaper/pads as a coping method for UI (71.6\% and 86.4\%, respectively). This discordance may be due to different UI severities in the investigated samples. The similar Barthel Index scores of participants with and without UI complaints in the present study indicates that the UI complaint was not so severe as to affect independence in daily activities, which may an explain the conflicting results regarding coping methods for UI. It is also possible that the participants excluded due to severe physical, cognitive, or mental deterioration in this study had more severe UI symptoms.

According to the results of IQ, which was used to evaluate knowledge of nursing home residents about UI, only 4.88 of the 14 items were given correct responses and no participants provided correct responses to all of the items. A number of studies have investigated UI knowledge in different populations by using either the IQ or other scales such as Prolapse and Incontinence Knowledge Quiz (PIKQ) and Urinary Incontinence Knowledge Scale. ${ }^{11-13,17-23)}$ However, to our knowledge, no study has focused on UI knowledge among nursing home residents. The mean number of correct IQ responses was 9.29 (66.4\%) in 18-30-year-old American women $^{17)}$; 6.16 in white and 5.46 in minority women ${ }^{11)}$; and 4.85 in community-dwelling Korean-American women above 30 years of age. ${ }^{12)}$ Shah et al. ${ }^{18)}$ reported that more than half of the PIKQ items were correctly answered by gynecology and urogynecology patients. Richter et al. ${ }^{19)}$ found that the level of knowledge about UI was $82 \%$ in young adults and was related to the high educational level of the participants. Liebergall-Wischnitzer et al. ${ }^{20)}$ reported a moderate UI knowledge of community-dwelling Israeli women of child-bearing age, which increased with higher age and education level. The findings of these studies showed that knowledge about UI in nursing home residents in the present study was similar to that of community-dwelling Korean-American women above 30 years of age and lower than that in other samples. This may be due to differences in age, education, and sociocultural characteristics of the populations in these studies.

The analyses of correct and incorrect responses to IQ items revealed that most of the nursing home residents considered UI to be a natural result of aging, that not much could be done other than using a pad/diaper, and that the best treatment for UI was surgery. In addition, they were also unaware that exercises could help to control UI. Keller ${ }^{21)}$ reported that women over 55 years of age had misconceptions about the causes and treatability of UI and that only 37\% of women with UI sought treatment. Mandimika et al. ${ }^{22)}$ reported a global lack of knowledge about UI risk factors, prevention strategies, and treatment options in community-dwelling women aged 19-98 years. Yuan and Williams ${ }^{13)}$ and Day et al. ${ }^{23)}$ also reported that both community-dwelling older individuals in China and community-dwelling women above 50 years of age had insufficient knowledge about the risk factors, symptoms, 
prevention, treatment and coping methods of UI and considered UI to be a natural result of aging. These findings of the previous studies are concordant with the findings of the current study, indicating the unmet educational needs relating to UI in different parts of societies.

To our knowledge, this study is the first to assess UI knowledge among nursing home residents; therefore, its findings are important for the literature. However, recruiting nursing home residents of only one city and not including nursing home residents from different geographical regions are limitations in this study. Therefore, it is necessary to validate these findings by evaluating UI knowledge in larger-scale studies including participants from nursing homes in different geographical regions.

The findings of the present study indicate the need to improve the knowledge and awareness of UI among nursing home residents. Educational programs developed for this purpose should focus on the causes, risk factors, coping methods, and treatment options of UI. In addition, health care professionals in nursing homes should be included in these educational programs and the feasibility of conservative treatment approaches such as physiotherapy and behavior training, which can be effective in UI management, should be improved.

\section{CONFLICTS OF INTEREST DISCLOSURES}

The researchers claim no conflicts of interest.

\section{ACKNOWLEDGMENTS}

This research (Project Grant Number 17/197 and the title “Nursing Home Residents' Level of Knowledge About Urinary Incontinence") has been granted by Muğla Sıtkı Koçman University Research Projects Coordination Office. The authors thank Ömer Günay (physical trainer - Abide Hasan Nuri Öncüer Nursing Home), and İsmail Uysal, (physiotherapist - Fethiye Nursing Home) for their valuable help in collecting data for the study.

\section{REFERENCES}

1. Ueda T, Tamaki M, Kageyama S, Yoshimura N, Yoshida 0. Urinary incontinence among community-dwelling people aged 40 years or older in Japan: prevalence, risk factors, knowledge and selfperception. Int J Urol 2000;7:95-103.

2. Skotnes LH, Hellzen 0, Kuhry E. Perceptions and barriers that influence the ability to provide appropriate incontinence care in nursing home residents: statements from nursing staff. Open $\mathrm{J}$ Nurs 2013;3:437-44.

3. Skotnes LH, Omli R, Romild U, Hellzen 0, Kuhry E. Urinary incontinence in Norwegian nursing home residents. Open J Nurs 2012;2:116-22.

4. Kim S, Park JH, Ahn H, Lee S, Yoo HJ, Yoo J, et al. Risk factors of geriatric syndromes in Korean population. Ann Geriatr Med Res 2017;21:123-30.
5. Lee SY, Kim SW, Sun WS, Cho HJ. Health status for the elderly living in a home for the aged. J Korean Geriatr Soc 2001;5:240-9.

6. Arikan E, Ozcan E, Bardak A, Ketenci A. Urinary incontinence in women living in a rest home. Turk J Geriatr 2002;5:7-10.

7. Olgun N, Eti Aslan F, Yucel N, Onturk Kan Z, Lacin Z. Assessment of health status of the elderly. ACU Saglik Bil 2013;4:72- 8.

8. Cankurtaran F, Soyuer F, Akin S. Urinary incontinence problem in elderly people living in rest home and it's relationship with mobility. Gumushane Univ J Health Sci 2015;4:594-603.

9. Rijal C, Hakim S. Urinary incontinence in women living in nursing homes: prevalence and risk factors. Indones J Obstet Gynecol 2014;2:193-8.

10. Jerez-Roig J, Santos MM, Souza DL, Amaral FL, Lima KC. Prevalence of urinary incontinence and associated factors in nursing home residents. Neurourol Urodyn 2016;35:102-7.

11. Kubik K, Blackwell L, Heit M. Does socioeconomic status explain racial differences in urinary incontinence knowledge? Am J Obstet Gynecol 2004;191:188-93.

12. Kang Y. Knowledge and attitudes about urinary incontinence among community-dwelling Korean American women. J Wound Ostomy Cont Nurs 2009;36:194-9.

13. Yuan H, Williams BA. Knowledge of urinary incontinence among Chinese community nurses and community-dwelling older people. Health Soc Care Community 2010;18:82-90.

14. Saxer S, de Bie RA, Dassen T, Halfens RJ. Nurses' knowledge and practice about urinary incontinence in nursing home care. Nurse Educ Today 2008;28:926-34.

15. Kara KC, Çıtak Karakaya İ, Tunalı N, Karakaya MG. Reliability and validity of the Incontinence Quiz-Turkish version. J Obstet Gynaecol Res 2018;44:144-50.

16. Branch LG, Walker LA, Wetle TT, DuBeau CE, Resnick NM. Urinary incontinence knowledge among community-dwelling people 65 years of age and older. J Am Geriatr Soc 1994;42:1257-62.

17. Tremback-Ball AJ, Levine AM, Dawson G, Perlis SM. Urinary incontinence knowledge among women 18-30 years of age. J Women Health Phys Therap 2008;32:17-22.

18. Shah AD, Massagli MP, Kohli N, Rajan SS, Braaten KP, Hoyte L. A reliable, valid instrument to assess patient knowledge about urinary incontinence and pelvic organ prolapse. Int Urogynecol J Pelvic Floor Dysfunct 2008;19:1283-9.

19. Richter LA, Gutman RE, Tefera E, Estep A, Iglesia CB. Knowledge of erectile dysfunction and pelvic floor disorders among young adults: a cross-sectional study. Can J Urol 2015;22:7715-9.

20. Liebergall-Wischnitzer M, Cnaan T, Hochner H, Paltiel O. Selfreported prevalence of and knowledge about urinary incontinence among community-dwelling Israeli women of child-bearing age. J Wound Ostomy Cont Nurs 2015;42:401-6.

21. Keller SL. Urinary incontinence: occurrence, knowledge, and attitudes among women aged 55 and older in a rural Midwestern setting. J Wound Ostomy Cont Nurs 1999;26:30-8.

22. Mandimika CL, Murk W, Mcpencow AM, Lake AG, Miller D, Connell KA, et al. Racial disparities in knowledge of pelvic floor disorders among community-dwelling women. Female Pelvic Med Reconstr Surg 2015;21:287-92.

23. Day MR, Patricia LW, Loughran S, O'Sullivan E. Community- 
dwelling women's knowledge of urinary incontinence. $\mathrm{Br} \mathrm{J}$ Community Nurs 2014;19:534-8.

24. Demirci N, Basar FK, Suzer F, Aba YA, Ataman H. Urinary incontinence in women in nursing homes and its effect on life quality. Firat Saglik Hizmetleri Dergisi 2011;6:85-101.

25. Göral Türkcü S, Kukulu K. Urinary incontinence and quality of life of women living in nursing homes in the Mediterranean region of Turkey. Psychogeriatrics 2017;17:446-52.

26. Ergun A, Toptaner NE, Bicakci T, Baran S, Akkaya G, Ekim N. Effect of urinary incontinence on quality of life (SF-36) of the elderly living in nursing homes. Akad Geriatri 2011;3:159-67.

27. Gungen C, Ertan T, Eker E, Yasar R, Engin F. Reliability and validity of the standardized Mini Mental State Examination in the diagnosis of mild dementia in Turkish population. Turk Psikiyatri Derg 2002;13:273-81.

28. Kucukdeveci AA, Yavuzer G, Tennant A, Suldur N, Sonel B, Arasil T. Adaptation of the modified Barthel Index for use in physical medicine and rehabilitation in Turkey. Scand J Rehabil Med 2000;32:87-92.

29. Cetinel B, Ozkan B, Can G. The validation study of ICIQ-SF Turkish version. Turk Uroloji Dergisi 2004;30:332-8.

30. Pinar SE, Demirel G. Examination of daily life activities, self-care age- ncy and life satisfaction of middle-aged and elderly individuals living in a nursing home. YSAD-EIRJ 2016;9:39-52.

31. Berberoglu U, Gul H, Eskiocak M, Ekuklu G, Saltik A. some sociodemographic specialities and daily activities of the elderly people according to the Katz index who live in edirne rest house. Turk Geriatri Dergisi 2002;5:144-9.

32. Jumadilova Z, Zyczynski T, Paul B, Narayanan S. Urinary incontinence in the nursing home: resident characteristics and prevalence of drug treatment. Am J Manag Care 2005;11(4 Suppl):S112-20.

33. Na HR, Park MH, Cho ST, Lee BC, Park S, Kim KH, et al. Urinary incontinence in Alzheimer's disease is associated with Clinical Dementia Rating-Sum of Boxes and Barthel Activities of Daily Living. Asia Pac Psychiatry 2015;7:113-20.

34. Lee SH, Cho ST, Na HR, Ko SB, Park MH. Urinary incontinence in patients with Alzheimer's disease: relationship between symptom status and urodynamic diagnoses. Int J Urol 2014;21:683-7.

35. Jung HB, Choi DK, Lee SH, Cho ST, Na HR, Park MH. Correlation between overactive bladder symptom score and neuropsychological parameters in Alzheimer's disease patients with lower urinary tract symptom. Int Braz J Urol 2017;43:256-63. 